\title{
Should We Trust the Results of Multivariate Analysis?
}

\author{
Alain Braillon
}

Received: 22 July 2009 /Accepted: 30 November 2009/Published online: 22 December 2009

(C) 2009 The Society for Surgery of the Alimentary Tract

In 66 patients, Shiba et al. studied 11 variables for early recurrence of HCC, ten for disease-free survival and ten for overall survival. ${ }^{1}$

Too few patients, too many variables for the guidelines on subject to variable ratio for multivariate statistical analysis. $^{2}$

Moreover, using cut-points to derive subgroups is not appropriate when there is a continuous distribution of the values with no obvious modal values.
Lastly, $p$ values must be adjusted for multiple testing, in this case three.

\section{References}

1. Shiba H, Ishida Y, Wakiyama $\mathrm{S}$ et al. Negative impact of blood transfusion on recurrence and prognosis of hepatocellular carcinoma after hepatic resection. J Gastrointest Surg 2009. Published online: 7 July 2009. doi:10.1007/s11605-009-0963-y

2. Kline P. An Easy Guide to Factor Analysis. London: Routledge, 1994.

A. Braillon $(\bowtie)$

Hepatology and Public Health, University Hospital,

80000 Amiens, France

e-mail: braillon.alain@chu-amiens.fr 